\title{
VARIATIONS IN MESOSPHERIC NEUTRAL DENSITIES FROM RAYLEIGH LIDAR OBSERVATIONS AT UTAH STATE UNIVERSITY
}

\author{
David L. Barton ${ }^{1}$, Vincent B. Wickwar ${ }^{1 *}$, Joshua P. Herron ${ }^{2}$, Leda Sox ${ }^{1}$, Luis A. Navarro ${ }^{1}$ \\ ${ }^{I}$ Physics and CASS, Utah State University, Logan, UT 84322, USA, *Email: \\ vincent.wickwar@gmail.com \\ ${ }^{2}$ Space Dynamics Lab, Utah State University, Logan, UT 84322, USA
}

\begin{abstract}
A Rayleigh lidar was operated from 1993 to 2004, at the Atmospheric Lidar Observatory (ALO; $41.7^{\circ} \mathrm{N}, 111.8^{\circ} \mathrm{W}$ ) at the Center for Atmospheric and Space Sciences (CASS) on the campus of Utah State University (USU). Observations were carried out on over 900 nights, 729 of which had good data starting at $45 \mathrm{~km}$ and going upward toward $90 \mathrm{~km}$. They were reduced for absolute temperatures and relative neutral number densities. The latter at $45 \mathrm{~km}$ can be put on an absolute basis by using atmospheric models that go up to at least $45 \mathrm{~km}$. The models' absolute number densities at $45 \mathrm{~km}$ are used to normalize the lidar observations, thereby providing absolute densities from 45 to $90 \mathrm{~km}$. We examine these absolute density profiles for differences from the overall mean density profile to show altitudinal structure and seasonal variations.
\end{abstract}

\section{INTRODUCTION}

Observing neutral density throughout the mesosphere is challenging, as has been discussed in relation to the development of the NRLMSISe00 empirical model [1]. The available instrumentation, such as balloons, reach up to $\sim 30 \mathrm{~km}$, while rockets are launched infrequently. For the thermosphere, densities are obtained from satellites and incoherent scatter radars.

However, ground-based, Rayleigh-scatter lidars, such as the ALO-USU Rayleigh-scatter lidar, can provide a solution. Their mesospheric observations can provide absolute temperatures and relative neutral number densities in the $35 \mathrm{~km}$ to $115 \mathrm{~km}$ or so altitude region [e.g., 2, 3].

An absolute scale can be applied to these relative densities by using empirical and reanalysis models that overlap with the Rayleigh data. The next section, Section 2, describes both the methodology for creating a pseudo-density climatology for a composite year from the relative densities and for using four models to apply absolute scales to this pseudo-density climatology. Section 3 describes the results found for the altitudinal and seasonal variations in the neutral number densities about an absolute mean profile during the composite year. It provides some conclusions about these variations and indicates future directions.

\section{METHODOLOGY}

There are two steps to finding the mesospheric neutral number density climatology. The first is to use the Rayleigh lidar observations to make a climatology of relative number density profiles over a composite year. For this, all the densities at $45 \mathrm{~km}$ are normalized to a constant. The second is to apply estimates of absolute densities at $45 \mathrm{~km}$ to scale the observed relative densities.

\subsection{USU Relative Density Variations}

The ratio of major mesospheric neutral constituents, $\mathrm{N}_{2}$ and $\mathrm{O}_{2}$, is assumed constant, giving rise to a constant Rayleigh backscatter coefficient in the mesosphere. Above $45 \mathrm{~km}$, the atmospheric transmission is taken to be 1.00 . Under these conditions, the lidar return multiplied by range-squared gives the relative neutral number density. The densities from each of the 729 nights, for which the data extend down to 45 $\mathrm{km}$, were included in this work. The all-night averaged density profiles were then scaled to a constant at $45 \mathrm{~km}$.

These observations occurred over 11 years. However, what is most meaningful is a climatology that shows how the densities vary over the course of a year. Accordingly, a composite year is created. For each day in this composite year, the nighttime densities at each altitude are averaged over all the nights within a 31-day window, centered on that night in each of the 11 years. In early January, the 31-day window includes nights from the previous December and, 
in late December, it includes nights from the next January. This averaging, applied to the norma-

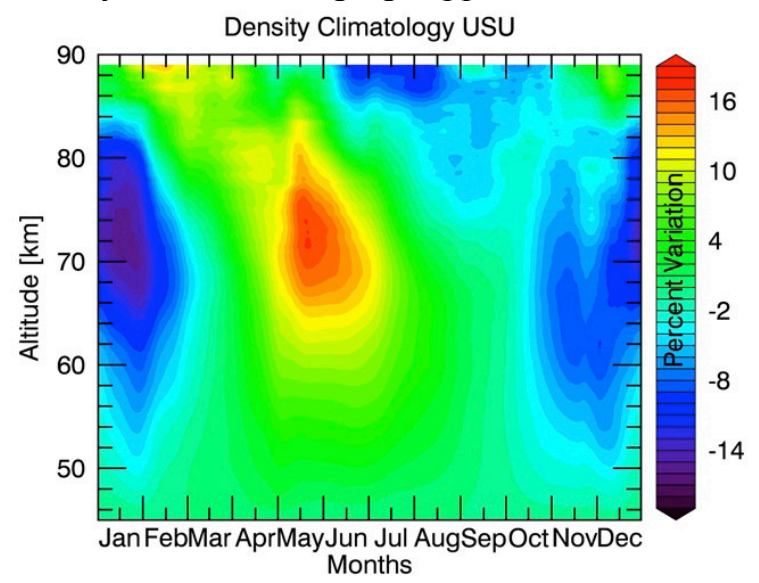

Figure 1. Climatology of relative density variations for a composite year derived from the ALO Rayleigh lidar observations. For each day, it shows the percentage variation at each height from the average annual density.

lized densities, produces a pseudo-density climatology (not shown) for the composite year.

With densities varying by over a factor of 600 between 45 and $90 \mathrm{~km}$, they would have to be displayed on a semilog plot, which would make it extremely difficult to see seasonal variations that are on the order of only $30-45 \%$. To better display these small variations, all 365 nights in the composite year are averaged together to find a mean or reference profile, $\langle n(h)\rangle$. Then, at each altitude, $h$, the percentage density difference $N(h)$ for each night's composite density $n_{31}(h)$ from the mean annual density $\langle n(h)\rangle$ is calculated as

$$
N(h)=100 \times\left[n_{31}(h)-\langle n(h)\rangle\right] /\langle n(h)\rangle .
$$

These percentage differences are shown in Figure 1.

\subsection{USU Absolute Densities Variations}

While Figure 1 does show significant variations in the observed relative densities with both altitude and season, these variations would be more meaningful if they were tied to an absolute density at $45 \mathrm{~km}$. This can be done by referring to several appropriate atmospheric models that go up to at least $45 \mathrm{~km}$ altitude. Four models, instead of one, were used to give an indication of the variability in this normalization. They include an empirical model, the NRLMSISe00 model (MSIS) [1], which is used extensively as a reference, three retrospective, reanalysis models that combine both first principle calculations and observations. The Climate Prediction Center model (CPC) [4,5] is the oldest of those being considered. It goes up to $1 \mathrm{hPa}$, which is just above $45 \mathrm{~km}$. The ECMWF model (ERA Interim) [6] is more recent. It, too, goes to $1 \mathrm{hPa}$. NASA's Modern-Era Retrospective analysis for Research and Applications model (MERRA) [7] goes to $0.1 \mathrm{hPa}, \sim 65 \mathrm{~km}$.

For each model, the number density was found at $45 \mathrm{~km}$ for ALO for each of the 729 observed days. For the MSIS model, this was straight forward as the densities above any point on any day are calculated as a function of altitude. For the reanalysis models, this was more involved. Profiles of pressure and temperature are given in their respective databases as a function of geopotential altitude on a global grid for every day during a period that includes the ALO observations. These geopotential altitudes were converted to geometric altitudes and interpolated to find the temperatures and pressures at $45 \mathrm{~km}$. The ideal gas law then gave the number densities.

As previously, a composite year was created for the four model-dependent sets of $45-\mathrm{km}$ density values, which are shown in Figure 2. The four curves have similar shapes, showing $\sim 30 \%$ greater density in summer than in winter. They also have a spread, with the highest densities being $20-30 \%$ greater than the lowest in all seasons. This spread is impressively small, considering that these are independent models, two of which are at their upper altitude limit.

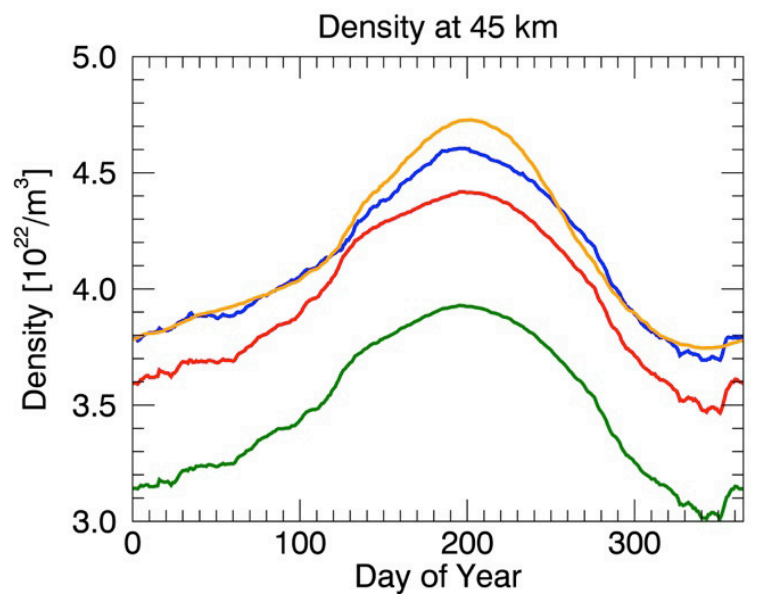

Figure 2. The 45-km absolute densites during a 
composite year for the MSIS (Yellow), CPC (Blue), MERRA (Red), and ERA Interim (Green) models.
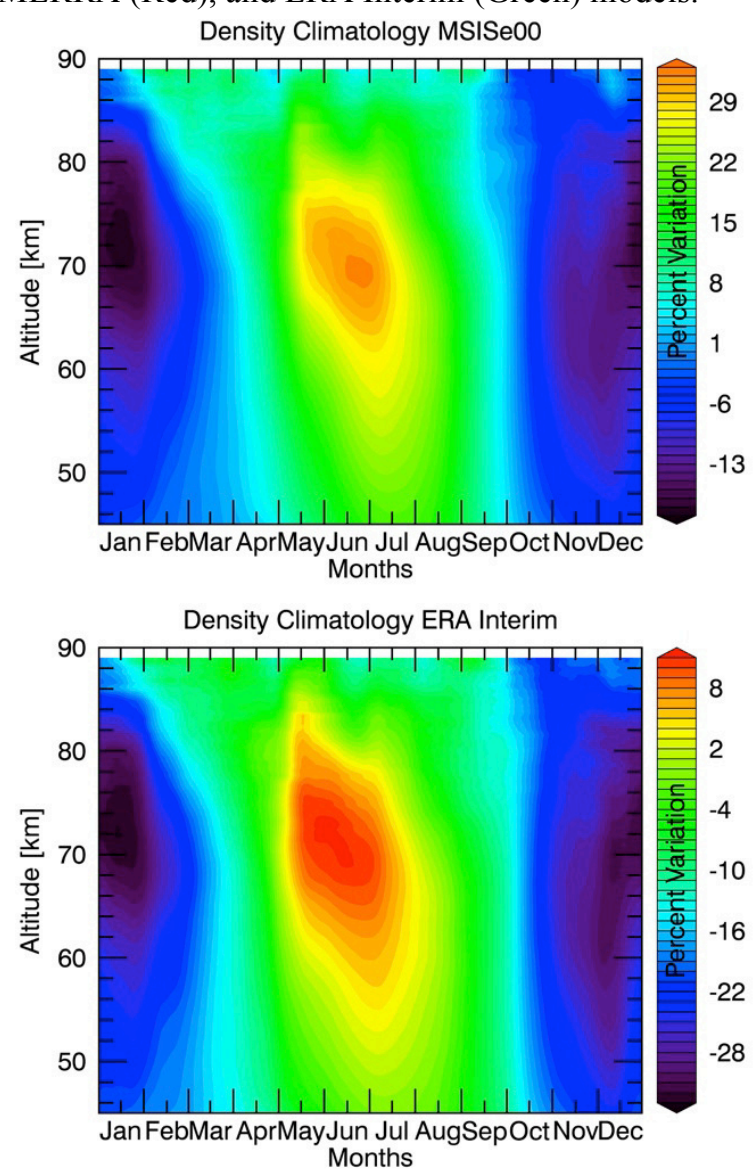
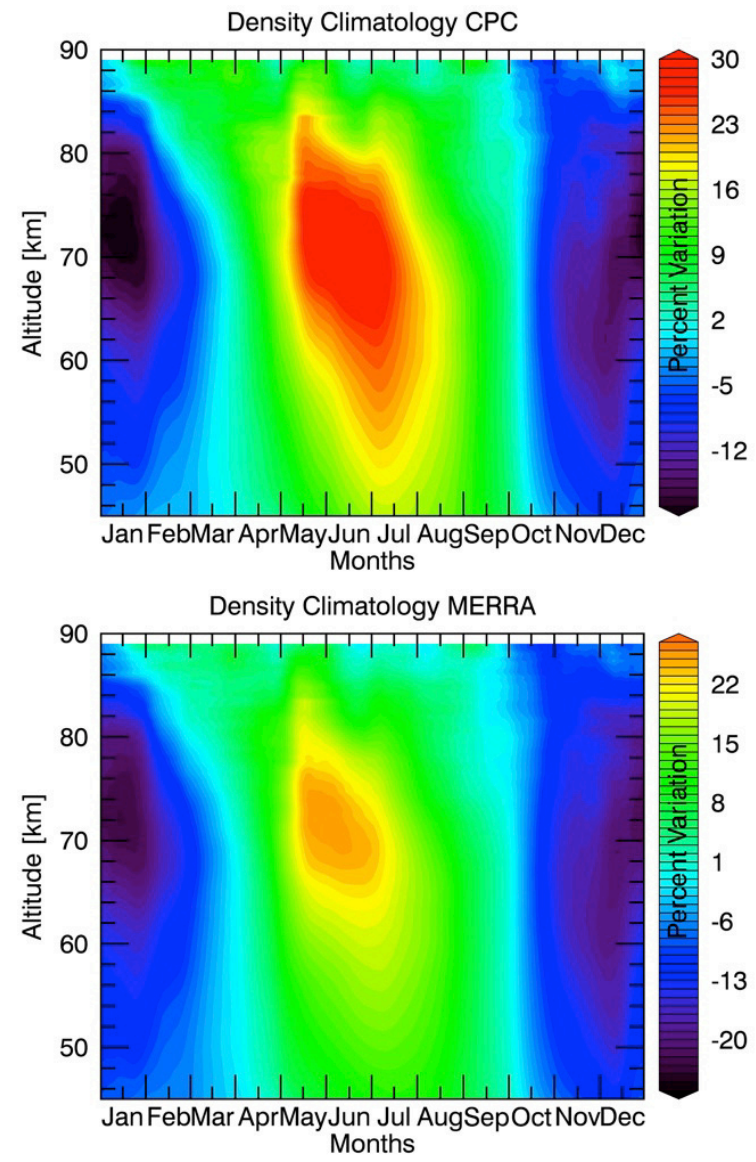

Figure 3. Climatologies of density variations from a mean absolute density profile for a composite year derived from the ALO Rayleigh lidar observations normalized to the four models at $45 \mathrm{~km}$. The models are MSIS (upper left), CPC (upper right), ERA Interim (lower left) and MERRA (lower right). (The color scale is different for each model.)

By applying these $45-\mathrm{km}$ density values to the observed relative density profiles, four sets of absolute number-density profiles are created. From these, four climatologies are formed (but not shown), each giving absolute number densities between 45 and $90 \mathrm{~km}$ over a composite year.

The four absolute densities at each altitude for each day of the composite year are averaged together to find an overall mean absolute density profile. The differences from this overall mean are then calculated for each model using the equivalent of Equation 1, displaying the results as percentage variations in the four parts of Figures 3 .

\section{RESULTS AND CONCLUSIONS}

The four absolute number density curves in Figure 2 have similar shapes, showing an annual variation at $45 \mathrm{~km}$, over the composite year, that is $\sim 30 \%$ greater in summer than in winter. The maximum is near mid July (day 200); the minimum near mid December (day 350). This asymmetry in the rise and fall of the density suggests contributions of semiannual and perhaps higher order variations, even in this region dominated by solar radiation. The curves have a small spread. The ordering from highest to lowest number density is MSIS, CPC, MERRA, and ERA Interim, with MSIS being 20-30\% greater than ERA Interim. That they are not closer together reflects the limitations in our current state of knowledge of the absolute densities at $45 \mathrm{~km}$.

The four sets of density values at $45 \mathrm{~km}$, applied to the relative densities from the lidar, provide absolute number density profiles throughout most of the mesosphere, 45-90 km. For reference, a mean profile was created from the four sets of density profiles in the composite year. For each 
model, the differences from the mean are shown as percentages in Figure 3.

In the region above $65 \mathrm{~km}$, which is usually thought to be dominated by dynamics, the difference profiles show a summer, density maximum that extends from May well into July. It is centered at $72 \mathrm{~km}$, but extends from 45 to $85 \mathrm{~km}$. Above $80 \mathrm{~km}$, the maximum is in mid May, whereas below $62 \mathrm{~km}$ it is in early July. They also show a winter density minimum above $65 \mathrm{~km}$ in mid January that is centered near $72 \mathrm{~km}$. It runs from December through January. At $70 \mathrm{~km}$, winter extends about 6 months, from a week into October until the beginning of April. In addition, below $65 \mathrm{~km}$, there is another deep minimum in late November and early December. This minimum extends to a much lower altitude than the January minimum.

The summer-to-winter transition in the fall is marked by a very sharp decrease in density over the same two weeks at the beginning of October at all altitudes. No such sharp increase occurs in the spring at a given time. Instead, the winter-tospring transition appears to propagate down from 90 to $70 \mathrm{~km}$ from early January to early April. At $70 \mathrm{~km}$, the transition takes place over about two weeks. At lower altitudes, it occurs earlier and more gradually. At $45 \mathrm{~km}$ it starts in January and takes 3 months.

This study suggests some future work. Given these new, absolute densities from $45-90 \mathrm{~km}$, they should be compared to those from the MSIS model, which covers this whole region, and to the MERRA model, which go up to $0.1 \mathrm{hPa}, \sim 65 \mathrm{~km}$.

It also suggests significant observational improvements at USU. One is to extend the lidar observations downward to overlap better with absolute values from the reanalysis models or even directly with balloons. Rayleigh observations could be extended to between 30 and $35 \mathrm{~km}$. Ramanscatter observations could extend the observations to about $15 \mathrm{~km}$. A second is a more sensitive Rayleigh system to extend the observations upwards into the lower thermosphere. Initial steps in this direction have been taken [2].

Going beyond USU, a major improvement would be to develop a simpler and more affordable Rayleigh system, which would cover this extended altitude range, and could be acquired and operated by many smaller research groups around the world to form a global observing network.

\section{ACKNOWLEDGMENTS}

David Barton would like to acknowledge financial support from USU, the Physics Dept, and the College of Science. Leda Sox would like to acknowledge the Physics Dept's Blood and Gene Adams Scholarships. Many thanks to Dr. Doug Drob of NRL for the MSIS algorithm and to Dr. Bill Randel of NCAR for the CPC data and discussions. Many thanks to ECMWF for permitting access to their database and use of the ERA Interim model, and to similarly to NASA for the MERRA reanalysis model and data. The lidar data were acquired with support from several grants from the Atmospheric Sciences Division of the National Science Foundation.

\section{REFERENCES}

[1] Picone, J. M., A. E. Hedin, D. P. Drob, and A. C. Aikin, 2002: NRLMSISE-00 empirical model of the atmosphere: Statistical comparisons and scientific issues, J. Geophys. Res., 107(A12), 1468-1483, doi:10.1029/2002JA009430.

[2] Wickwar, V. B., L. Sox, M. T. Emerick, J. P. Herron, D. L. Barton, 2015: Early temperatures observed with the extremely sensitive Rayleigh lidar at Utah State University, ILRC27.

[3] Herron, J.P., 2007: Rayleigh-Scatter Lidar Observations at USU's Atmospheric Lidar Observatory (Logan, UT) - Temperature Climatology, Temperature Comparisons with MSIS, and Noctilucent Clouds, PhD Dissertation, 156 pp, Utah State University, Logan, UT.

[4] Gelman, M. E., A. J. Miller, K. W. Jihnson, and R. N. Nagatani, 1986: Detection of long term trends in global stratospheric temperature from NMC analyses derived from NOAA satellite data. Adv. Space Res. 6, 17-26.

[5] Randel, W. J., et al., 2004: The SPARC Intercomparison of middle-atmosphere climatelogies, J. Climate, 17, 986-1003.

[6] Berrisford, P., et al., 2011: The ERA-Interim Archive, Version 2.0. ERA report series, 1. Technical Report, 23 pp, ECMWF. 
[7] Rienecker, M. M., et al., 2011: MERRA: NASA's modern-era retrospective analysis for research and applications, J. Climate, 24(14), 3624-3648. 